\title{
Las crisis financieras autónomas en Marx
}

\author{
Fernando Esteve Mora
}

Universidad Autónoma de Madrid

\section{José Manuel Rodríguez Rodríguez}

Universidad Autónoma de Madrid

\section{INTRODUCCIÓN}

El objetivo de Marx en El Capital era «poner al desnudo la ley económica del movimiento de la sociedad moderna» (C.I.Prefacio:23). Para ello Marx contaba con un método de investigación conformado por una aproximación metodológica al estudio del cambio: el llamado materialismo dialéctico, y una filosofía de la historia que se conoce como materialismo histórico . Con arreglo a la primera, el cambio ha de ser entendido no como un desenvolvimiento suave o evolutivo, no como el despliegue más o menos armonioso de unas capacidades insertas en una estructura, sino como resultado de los enfrentamientos entre opuestos, como fruto de contradicciones y antagonismos que se resuelven y superan cuando se genera —y eso es el cambio - una situación nueva que engloba anulándolos a los antes contrarios, situación nueva que no tarda mucho en revelarse dinámica, cambiante o lo que es lo mismo internamente contradictoria. En una palabra, para Marx todo cambio es fruto del antagonismo y la rivalidad. A diferencia de su maestro Hegel, Marx encuentra que las oposiciones y contradicciones que explican el cambio social no se dan en la realidad mental sino en la material. Para el materialismo dialéctico, el cambio ha de entenderse como resultado de las contradicciones entre el desarrollo de las fuerzas productivas y el marco de las relaciones sociales de producción en cada sociedad histórica, contradicciones abstractas que se encarnan o manifiestan de modo concreto en la oposición entre individuos agrupados en clases sociales definidas por su relación económica con el proceso de reproducción de la base económica de la sociedad. Visto desde la otra perspectiva complementaria, 
la del materialismo histórico, el cambio social es el fruto en cada período histórico del antagonismo entre las clases sociales: la «lucha de clases».

Ciertamente, la historia previa al surgimiento del capitalismo proporcionaba a Marx una buena confirmación empírica de sus puntos de vista. No era así difícil encontrar razones para el antagonismo social y las revoluciones en el llamado modo de producción asiático del antiguo Egipto y Mesopotamia, o en el modo de producción esclavista de la Roma clásica, o en el modo de producción feudal definidor para Marx de las sociedades medievales. Campesinos, esclavos y siervos de la gleba eran en todas estas sociedades evidentemente explotados por sacerdotes, amos y nobles, por lo que razones para el enfrentamiento generador del cambio nunca habían faltado y estaban a la vista.

Pero las cosas eran mucho más difíciles a la hora de explicar la dinámica de las sociedades capitalistas. En ellas, las relaciones que se dan entre los propietarios de los distintos medios de producción (bienes de capital y fuerza de trabajo) no son por lo general forzadas, pues a nadie se le obliga a participar en los mercados contra su voluntad, sino libres y voluntarias. Concretamente, en lo que respecta a las relaciones entre propietarios del capital y propietarios de la capacidad de trabajo, son generalmente relaciones libres de intercambio en los distintos mercados de trabajo. La consecuencia, como bien sabía Marx, es que si los intercambios son voluntarios no hay explotación y por lo tanto, tampoco antagonismo radical, pues dentro de los mercados los partícipes se benefician mutuamente. Podrán ciertamente disentir por el reparto relativo de las ganancias del intercambio, podrán pensar aquellos que crean haberse llevado la peor parte en un intercambio que los otros han ganando proporcionalmente más, o que no se lo merecen; sí, podrán pensar que no han ganado lo que esperaban pero lo que no podrán pensar es que han sido explotados. Marx repite así en multitud de ocasiones que los capitalistas, los propietarios de los medios de producción, no explotan a los trabajadores en los mercados de trabajo ni en los de bienes; luego en las relaciones de intercambio o de mercado habrá conflicto distributivo pero no habrá razones para el antagonismo pues no hay explotación. En consecuencia, Marx necesitaba encontrar en las sociedades de mercado capitalistas una auténtica relación de explotación entre clases, semejante a las que tan visiblemente aparecían en las sociedades históricas, que justificara el antagonismo, el motor del cambio social.

Marx encontró esa relación de explotación entre los capitalistas y los trabajadores en el proceso de producción. En su Teoría del valor-trabajo, elaborada a partir de la teoría clásica del valor en su formulación ricardiana, encontró la pieza analítica imprescindible para entender cómo un sistema aparentemente no explotador como lo era 
el sistema de mercado capitalista era sin embargo un sistema tan explotador y contradictorio como los que le habían precedido en la historia.

\section{LA TEORÍA DE LA EXPLOTACIÓN Y LAS CRISIS ECONÓMICAS}

El punto de partida de Marx son los bienes como mercancías, es decir como bienes intercambiables. Dada la heterogeneidad cualitativa de las mercancías, es necesario a la hora de explicar los precios o valores de cambio que hay entre ellas, el encontrar aquello que existe en todas ellas, una sustancia común y homogénea que permita compararlas cuantitativamente, de modo que sea la mayor o menor abundancia de esa «sustancia» común en una mercancía cualquiera la que explique su mayor o menor valor de cambio. Marx, siguiendo a los economistas clásicos, encuentra que hay dos cualidades comunes a toda mercancía producida: la de ser útil y la de ser fruto del trabajo humano, ya directo o ya indirecto (el trabajo contenido en los medios de producción). Marx, a la hora de explicar los valores de cambio, elige la segunda cualidad y señala que si una mercancía tiene un cierto valor de cambio respecto a otra (es decir, si se puede cambiar en cierta proporción con otra cualquiera) es porque tiene un determinado valor definido como la cantidad de trabajo socialmente necesario para producirla, o mejor dicho, reproducirla. Si, por las razones que sea, el dueño de una mercancía con un determinado valor logra que otro le dé a cambio otra mercancía de mayor valor, le habrá explotado (a sabiendas o no) pues habrá obtenido una ganancia en el intercambio a costa de la otra parte, pero no se puede pensar que tal transferencia de valor ocurrirá de modo habitual en los mercados, donde lo normal será que la competencia tenderá a hacer que se intercambien cantidades de mercancías de valor equivalente.

La consecuencia de lo anterior es que si como norma no hay explotación en los intercambios no se puede explicar la existencia de una de las categorías centrales de un sistema capitalista: los beneficios. En efecto, en cada proceso de producción se produce un valor añadido que es la suma del valor aportado por el trabajo (las horas de trabajo directo aportadas por los trabajadores a las mercancías que producen) y el valor de los medios de producción (el valor —o sea, las horas de trabajo que, como mercancías duraderas que son - transfieren en el proceso de producción a las mercancías producidas); en consecuencia se tiene que si los trabajadores reciben un pago (salario) correspondiente al valor que aportan y si los capitalistas se quedan con el valor que aportan sus medios de producción (en forma de amortizaciones por depreciación), no queda ningún excedente o remanente, ningún valor que justifique la existencia del beneficio. 
Pero beneficios, haberlos, haylos; y para Marx, son fruto de la explotación de los trabajadores, pero - hay que recalcarlo- esta explotación no se da en los mercados de trabajo. En ellos, los capitalistas pagan la mercancía que compran, la fuerza de trabajo de los trabajadores, y la pagan por su estricto valor (o sea, el tiempo necesario para la reproducción de la capacidad de trabajo) en forma de un salario que le permita a cada trabajador comprar aquellos bienes y servicios necesarios para su reproducción como trabajadores, cuyo valor (las horas de trabajo socialmente necesarias requeridas para su producción) es por tanto igual al valor de la mercancía que ellos - los trabajadores- venden. La explotación acontece, pues, no en el mercado de trabajo sino en el proceso de producción, donde los capitalistas les hacen trabajar a los trabajadores más horas que las que han comprado, es decir que los trabajadores aportan al proceso de producción más trabajo y, correspondientemente, más valor que el que contiene la mercancía fuerza de trabajo, y ese plustrabajo o en términos de valor, plusvalía, es la fuente de beneficios de los capitalistas. Marx en suma, gracias a la teoría del valortrabajo encuentra que en el sistema capitalista también hay explotación, hay por ello en él antagonismo y oposición que justifican la dinámica interna de las economías capitalistas caracterizada por un movimiento irregularmente cíclico punteado por crisis económicas.

El movimiento económico de la economía capitalista se deriva, para Marx, del proceso de valoración del capital. Marx define el capital como valor que se valoriza, es decir como valor que busca constantemente su expansión y para ello, para acrecentarse como tal valor, no le queda más remedio que trasmutarse y cambiar de forma (lo que Marx llama el proceso de circulación del capital) pasando obligadamente por una fase en que es capital-productivo, pues sólo el plustrabajo, el trabajo no pagado que realizan los trabajadores en los procesos de producción, genera un valor añadido o plusvalía. Así, inicialmente, al principio de su proceso de circulación, el capital aparece como capital-dinero en manos del capitalista, luego en una segunda etapa cuando ese dinero se invierte, el capital aparece como capital-productivo es decir, como el valor de los factores de producción (valor del capital fijo o capital constante y valor de la fuerza de trabajo contratada o capital variable, en terminología marxista) en un proceso productivo, más tarde tras el proceso de producción el capital cambia de nuevo de forma y toma la de capital-mercancía o mercancías producidas cuyo valor es ya mayor que el valor del capital-productivo en la medida que ya incorpora la plusvalía generada por los trabajadores en el proceso de producción, y finalmente el proceso de circulación termina cuando el capital vuelve a su forma inicial como capital-dinero una vez que el valor de las mercancías producidas aparece como dinero en manos otra vez del capitalista cuando logra venderlas. Si esa venta le reporta unos ingresos superiores a aquellos con 
los que empezó, el proceso de valorización del capital habrá tenido éxito, el capitalista habrá obtenido un beneficio, reflejo monetario de la plusvalía producida en el proceso de producción y de la que se ha apropiado por su posición dominante en el proceso de producción asociada al hecho de ser el propietario del capital fijo. Si ha obtenido un beneficio el capitalista cuenta, por tanto, con una mayor cantidad de capital-dinero con el que podría empezar un nuevo proceso de valoración a escala ampliada si lo convierte en una cantidad más grande de capital-productivo que la que usó en el proceso de circulación precedente (proceso de acumulación de capital).

Ser capitalista, por otro lado, no es en sí ninguna garantía para el éxito en la consecución de ese proceso de valorización, y así, en cada período, habrá muchas empresas que fracasen por las más diversas razones, por ejemplo debido a decisiones microeconómicas erróneas por parte de los capitalistas ya sea respecto a la organización del proceso de producción, la técnica utilizada o el tipo y cantidad de bienes o servicios producidos. Si un capitalista toma decisiones equivocadas en cualquiera de estos campos, ello implica que está comprometiendo su capital en un proceso de valorización más o menos ineficaz para ese propósito ya sea por el tipo de proceso de producción ya sea por su escala ${ }^{1}$, por lo que su capital tras recorrer el proceso de circulación acabará teniendo menos valor que al principio, es decir, que se desvaloriza. Pero la cuestión es la de si es posible y por qué razones pueden darse simultáneamente esas situaciones de desvalorización para muchos capitalistas, es decir, situaciones en que el proceso de valoración no se realiza con carácter general, situaciones pues de crisis económica. Para Marx, la trama de intercambios monetarios mediante la que se llevan adelante los procesos de circulación del capital implica la existencia de una separación temporal entre la venta de una mercancía y la compra de otra, lo que de por sí invalidaba la necesariedad de la Ley de Say en la medida que posibilitaba la ruptura de esa cadena de intercambios.

Pero el problema era explicar la razón de que se produjese tal interrupción general. Frente a la visión de los economistas ortodoxos que sostienen que las economías de mercado, a menos que se vean afectadas por algún shock externo (un avance técnico, un cambio psicológico en las expectativas o en la preferencia por la liquidez, un ascenso repentino del precio de algún recurso natural básico y general como el petróleo, una intervención externa de la autoridad económica que fija un tipo de interés distinto

\footnotetext{
1 Hay que agregar otra fuente de desvalorización del capital que Marx acentúa repetidamente. Se trata de la obsolescencia técnica. El progreso técnico desvaloriza al capital que está incorporado en un determinado equipo capital fijo al volverlo relativamente ineficiente.
} 
al «natural»), se encuentran en o están en camino hacia un equilibrio, para Marx, por el contrario, no hay tal equilibrio. El antagonismo entre capital y trabajo origina un conjunto de contradicciones internas que aparecen en la realidad económica en forma de crisis económicas recurrentes. El sistema capitalista, por lo tanto, sin necesidad de shocks exógenos negativos, pasa por situaciones dónde, de modo general, los capitalistas no pueden llevar adelante los procesos de valoración de sus capitales por lo que, consecuentemente, se interrumpen los procesos de circulación de capital. La economía entonces se estanca (el sistema no logra reproducirse), las empresas quiebran y el desempleo aumenta. Marx supone que el objetivo de cada capitalista es valorizar su capital a escala cada vez mayor, objetivo que cada capitalista se ve obligado a perseguir, deséelo o no subjetivamente, pues le viene impuesto por la competencia entre las empresas $^{2}$, por lo que la tasa de acumulación (es decir, la tasa de inversión) se convierte en la variable clave que explica el movimiento de la economía. En consecuencia, Marx apunta a la atenuación de la acumulación de capital, a la caída de las inversiones, como causa inmediata de una crisis económica.

Pero la cuestión entonces es la de cómo unos antagonismos entre clases sociales afectan negativamente a la tasa de acumulación de capital. Una de las respuestas es que ese antagonismo acaba por minar la rentabilidad de la que depende en último término la tasa de acumulación. Cabe hablar así de: a) crisis asociadas a la llamada ley de la tendencia descendente de la tasa de ganancia resultado de la progresiva acumulación de capital fijo derivada de la competencia entre los capitalistas, y b) crisis asociadas con la distribución de la renta que a su vez pueden ser de dos tipos, b.1) las crisis de realización de la plusvalía fruto de situaciones en las que la desigual distribución de la renta genera un problema de demanda efectiva, también llamadas crisis de subconsumo; y b.2) crisis de sobreacumulación, que surgen cuando tras un período de expansión económica, se ha llegado a una situación cercana al pleno empleo de modo que la plusvalía generada ya no puede aumentar sino más bien incluso decrecer debido al ascenso en los salarios, haciendo caer la tasa de ganancia.

En todos estos tipos de crisis hay que destacar dos puntos. En primer lugar, las crisis económicas «sirven» para restaurar las condiciones necesarias para que puedan

2 Obviamente, para Marx la competencia entre capitalistas no se parece en nada a la armoniosa relación no conflictiva entre empresas que bajo el calificativo de competencia perfecta describe, o mejor, imagina la economía ortodoxa. La visión de la competencia para Marx no difiere en nada de la visión schumpeteriana de la competencia como «destrucción creativa» (probablemente, Schumpeter gran lector y admirador de Marx (el Marx burgués se le llamaba) sacara de éste su visón de la competencia). 
repetirse con carácter general los procesos de acumulación de capital, es decir las crisis son funcionales al sistema capitalista y le «sirven» para restaurar las condiciones de rentabilidad del capital ya sea a través de la desvalorización del capital asociada a la quiebra de empresas, ya por la moderación salarial asociada al desempleo. En segundo lugar, que dado que en una economía de mercado las crisis aparecen como interrupciones del proceso de circulación del capital, las crisis siempre se manifiestan como crisis financieras pues se traducen en problemas financieros de las empresas (imposibilidad de poder vender sus productos a precios que sean rentables), pero no son crisis financieras autónomas porque realmente tienen su origen en el sector productivo o real de la economía puesto que es en la esfera de la producción donde se asienta la relación antagónica entre el capital y trabajo.

Sin embargo, en repetidas ocasiones, Marx considera que pueden existir crisis económicas que tengan su origen fuera del proceso de producción, en el propio proceso de circulación afectando más adelante al proceso de producción. Serían crisis económicas que se originan no en el sector real, sino en el financiero, auténticas crisis financieras. Así, ya en el libro I de El Capital, Marx distingue entre los problemas monetarios y financieros que acompañan a cualquier crisis en una economía de mercado, se origine la crisis en la esfera en que se origine, de las crisis financieras en sentido estricto:

Es preciso distinguir -dice Marx- la crisis monetaria de que hablamos aquí, y que es una fase de cualquier crisis, del tipo especial de crisis a la cual se le el mismo nombre, pero que sin embargo puede ser un fenómeno independiente, de modo que su acción sólo influya sobre la industria y el comercio por repercusión. Las crisis de esta clase tienen por eje el capital-dinero, y su esfera inmediata es, entonces, la de este capital: la banca, la Bolsa y las finanzas (C.I.iii:144).

Ahora bien, con arreglo al método de Marx , si hay crisis financieras autónomas respecto al proceso de producción, ello significa que debe haber contradicciones inherentes a los procesos financieros, contradicciones entre los grupos que se relacionan en esos procesos que las expliquen y justifiquen. Sin embargo, dado que los procesos financieros no son procesos productivos, sucede que en ellos no se va a encontrar el antagonismo entre capitalistas y trabajadores como «justificación» de las crisis financieras. Dicho de otra manera, con arreglo al método marxista, para que existan crisis financieras autónomas han de existir contradicciones entre los propios capitalistas que participan en esos procesos financieros, contradicciones al margen de la que enfrenta a capitalistas y trabajadores, pero que son relevantes como ella para explicar el movimiento de la economía capitalista. El hecho de que se plantee la posibilidad de existencia de crisis financieras 
autónomas, es decir, no explicadas de modo directo por la dinámica de la oposición entre capital y trabajo es, sin lugar a dudas, más que una posición minoritaria, una «herejía» dentro de la corriente de pensamiento marxista. La importancia del sector financiero fue, sin embargo, tempranamente reconocida por Rudolf Hilferding (Das Finanzkapital, 1910), quien señaló el papel del sistema financiero, no como una nueva fuente de contradicciones económicas para las economías capitalistas, sino para reforzar la contradicción entre capital y trabajo como consecuencia del estímulo a los procesos de concentración y centralización de capitales (lo que significa la concentración efectiva del poder de control sobre cada vez una mayor cantidad del capital de la sociedad en manos de un menor número de capitalistas) que el desarrollo del sistema financiero permite. No obstante, Hilferding, congruentemente con la importancia que daba al sector financiero, entendió las crisis como «perturbaciones de la circulación», como resultado de divergencias entre la oferta y la demanda entre los distintos sectores productivos causadas por el control cada vez mayor del aparato productivo por el sector financiero-bancario, es decir, como crisis de desproporcionalidad. Respecto a este tipo de crisis, y comentando la posición de Hilferding, Sweezy en su clásica descripción de la economía marxista, Teoría del Desarrollo Capitalista de 1942, afirma que «la desproporcionalidad es siempre una posible causa de las crisis, y es casi seguramente un factor de complicación en todas las crisis, sea cual sea la causa básica de éstas. Pero las desproporcionalidades que provienen del capitalismo sin plan, por su naturaleza, no son susceptibles de explicación en términos generales. Por esta razón su examen queda fuera del ámbito del sistema teórico de Marx puesto que la competencia entre capitalistas era un tema que Marx no pretendía analizar detalladamente, es muy natural que sólo de paso haya prestado atención a la desproporcionalidad como causa de las crisis» (Sweezy, 1972: 176-77). Pues bien, el objetivo de las páginas que siguen es señalar no sólo que esa competencia entre capitalistas y las crisis a que puede dar lugar ocupan una parte no pequeña del Libro III de El Capital por lo que no se puede afirmar que sean un factor marginal para el pensamiento de Marx, sino que en sí misma es un factor explicativo de primer orden a la hora de explicar el comportamiento cíclico de las economías capitalistas.

\section{LOS CONFLICTOS EN TORNO AL REPARTO DE LA PLUSVALÍA}

De modo deslavazado en el Libro III, Marx, sin olvidar en ningún momento la relación antagónica que opone a capitalistas y trabajadores, encuentra también que, en las economías capitalistas reales, dentro de cada uno de esos grupos genéricos hay subgrupos cuyas interrelaciones pueden ser conflictivas dando origen a antagonismos 
secundarios que han de tenerse en cuenta para tener una visión más precisa de las leyes de movimiento de esas economías.

Marx se refiere aquí, de modo fundamental, a las relaciones que distintos grupos de propietarios establecen entre sí a la hora de repartirse la plusvalía generada en el proceso de producción. Distingue así entre los propietarios de la tierra y demás recursos naturales escasos, que obtienen por el mero hecho de ser propietarios una parte de la plusvalía en forma de renta ; y tres distintos grupos de capitalistas según la función que realicen en la economía ${ }^{3}$ :

a) los capitalistas financieros, que no están comprometidos de modo directo en las actividades productivas pero son quienes ponen a disposición de los demás capitalistas (ya sean comerciales o industriales) su capital-dinero para que puedan financiar sus inversiones en capital fijo y salarios $\mathrm{u}$ otros activos o bienes caso de que no tengan suficientes medios. Esta relación financiera toma dos formas: la de capital-préstamo, a cambio del cual perciben parte de la plusvalía o del valor realizados por los otros capitalistas en sus empresas en forma de interés; y la de compra de acciones en los mercados primarios de valores emitidas por los demás capitalistas (incluyendo las emisiones que hacen ellos mismos cuando quieren captar fondos para sus préstamos o sus compras de acciones), obteniendo de ellas como rendimiento una parte de la plusvalía en forma de dividendos. Para Marx, en cuanto a su función como financiadores, no hay diferencias sustanciales entre prestamistas y accionistas tanto en su comportamiento como en su fuente de ingresos: la plusvalía generada en los procesos productivos. Ambos tipos de agentes son capitalistas financieros alejados de las tareas de organizar la producción y extraer la plusvalía.

En lo que respecta al tipo de interés, que determina los ingresos por intereses de los prestamistas, Marx recalca que no es el precio del capital ${ }^{4}$, y que su nivel está indeterminado $^{5}$. Tiene un límite máximo definido por la tasa de ganancia media (siendo

${ }^{3}$ Se distinguen tres grupos de capitalistas aunque, como resultará obvio en la exposición, lo que se distingue es entre tres funciones que puede hacer un capitalista, pues hay capitalistas que hacen dos o tres de esas funciones.

${ }^{4}$ Aunque es consciente de la existencia de una diversidad de tipos de interés en función de diferentes circunstancias, Marx no le presta atención hablando del tipo de interés en general.

5 «Si se quiere denominar al interés precio del capital-dinero, se emplea una forma irracional del precio que se contradice absolutamente con la noción de precio de la mercancía» (C.III.xxi:364). El capital tiene un valor que se expresa en dinero que nada tiene que ver con el tipo de interés. 
cero el tipo mínimo ${ }^{6}$ ), pero dentro de esos valores extremos no hay una causa técnica (al estilo de la productividad marginal del capital ${ }^{7}$ ) o psicológica (tasa de preferencia temporal) que justifique un determinado tipo de interés como «natural», sino que será en cada momento determinado por la demanda y oferta de fondos prestables.

b) los capitalistas comerciales cuyas actividades de intermediación y compraventa en los mercados de mercancías ${ }^{8}$ y de dinero no son actividades productivas de valor por muy necesarias que sean para la realización del proceso de circulación y valoración del capital, y por lo tanto no generan plusvalía. Dado que no generan valor, la financiación de las actividades comerciales así como los beneficios de los capitalistas a ellas dedicados proviene ineludiblemente de la plusvalía que se genera en las actividades realmente productivas de valor. Es decir que aunque las actividades de intermediación no generan plusvalía, los capitalistas comerciales participan en la plusvalía generada y obtienen una tasa de ganancia por el capital que invierten en esas actividades que tiende a equiparase a la tasa general o tasa media de ganancia que obtienen los capitalistas en los procesos que producen valor.

Marx sólo considera explícitamente estos dos tipos de capitalistas intermediarios: los que se dedican a la compraventa de mercancías ${ }^{9}$ y los que se dedican a la intermediación dineraria ${ }^{10}$ (las operaciones de «pagos», «cobros», «cálculo de balances», «actos de compensación», «manejo de cuentas corrientes», etc.), dejando de lado una consideración explícita de otros capitalistas dedicados a la intermediación que comercian: 1) con bienes que no son mercancías en el sentido de no ser resultado de procesos

6 Situación en la que todos los capitalistas «trabajan» con su propio capital. Situación, por tanto, sólo imaginable.

7 Marx se burla aquí de (un tal) Karl Arnd, que afirmaba haber descubierto una justificación de una tasa «natural» de interés en la tasa de crecimiento del volumen de madera en los arboles de los bosques europeos que es independiente del valor de cambio de la madera: « ¿Cuán curioso es, en el caso de los árboles que se las arreglen para que su crecimiento resulte independiente de su valor de cambio!...Esto merece denominarse "la tasa de interés de origen silvestre"»(C.III.xxii:373).

${ }^{8}$ Marx se refiere a actividades de intermediación en sentido estricto, o sea excluyendo todo tipo de transporte, almacenamiento, y distribución al por menor que son actividades productivas de valor.

9 Para evitar confusiones, ha de tenerse en consideración que, para Marx, de la actividad comercial se excluyen todas las actividades de transporte, distribución al por mayor, almacenamiento, etc., que son actividades productivas de valor.

10 Hay que tener cuidado y no confundir a estos intermediarios financieros con los prestamistas, es decir con los capitalistas financieros. 
de reproducción (p.ej., las obras de arte), 2) con la propiedad de recursos naturales (ya sean de uso productivo o consuntivo) que no son mercancías por no ser fruto del trabajo humano (p.ej., la tierra, las minas, etc.) y 3 ) con los activos financieros (acciones, obligaciones, letras, deuda pública, etc.) que tampoco son en sí mercancías.

Ahora bien, el que no reciban una consideración particular no significa que Marx los considerara irrelevantes sino todo lo contrario, como más adelante se verá. Y, en efecto, Marx es plenamente consciente de que, si bien los mercados de obras de arte $\mathrm{u}$ otros bienes únicos puede que no sean muy importantes a escala general, no puede decirse lo mismo de los mercados donde se intercambian la propiedad de los recursos naturales ni de los mercados bursátiles donde se intercambian los activos financieros, mercados estos últimos cuyo desarrollo en el último siglo y medio ha adquirido unas proporciones y una importancia económica que Marx no podía ni imaginar. Marx identificó dos de los factores básicos para su desarrollo: la expansión de las sociedades por acciones y el desarrollo del que él llamaba sistema de crédito o sector financiero de la economía, pero obviamente no pudo ver ante sus ojos sino las primeras manifestaciones del desarrollo de la financiarización de la economía que junto con la globalización -que también por otra parte previó- constituyen los dos elementos que definen la economía de nuestros días.

Al igual que los capitalistas intermediarios mercantiles o monetarios han de ganar en el proceso de compraventa de mercancías la tasa de ganancia media o general del capital, también aquellos que se dedican a estas otras actividades de intermediación (agentes de Bolsa, bancos de inversión, fondos de inversión de todo tipo, Hedge Funds, etc.) comprando y vendiendo títulos de propiedad y todo tipo de títulos y activos financieros ${ }^{11}$ habrán de obtener una rentabilidad equivalente para que dediquen su capital dinero a esa intermediación. Pero, en tanto que parece clara la forma en que los capitalistas comerciales consiguen valorizar su capital y obtienen sus beneficios a partir de la plusvalía generada en el proceso de producción de los bienes que compran y venden ${ }^{12}$ (incluyendo los beneficios de los capitalistas que se dedican a comerciar

11 Incluyendo títulos hipotecarios y toda la parafernalia que la innovación financiera ha producido (productos financieros estructurados, futuros, derivados y opciones de compra y venta, Credit Default Swaps (CDS), Collateral Debt Obligation (CDO),...)

12 Esos beneficios comerciales, como Marx explica, no resultan de que los intermediarios pongan un «recargo» sobre el valor que resulta del proceso de producción, como enseñan las apariencias, aquí también, las apariencias engañan, y la ganancia comercial no resulta sino de la apropiación por parte del capitalista comercial de una porción del valor ya creado en el proceso de producción de los bienes que comercializa. 
con el dinero ${ }^{13}$ ), resulta sin embargo mucho más difícil entender de dónde surgen los beneficios que se «generan» en los mercados bursátiles y, en general, en los mercados de títulos ${ }^{14}$.

Como se ha dicho, Marx no los analizó específicamente, pero sí usó en distintos lugares de un concepto que se revela enormemente útil para su análisis. Se trata del concepto de capital ficticio. Por él Marx entendía todo título negociable emitido en contrapartida de un préstamo, ya sea a empresas (letras de cambio, obligaciones) o al Estado (deuda pública), o como reconocimiento de la participación en la financiación de las inversiones efectuadas por una empresa (acciones), o a particulares (p.ej., títulos con respaldo hipotecario), y que son para su propietario una fuente de renta que se puede capitalizar («se denomina capitalización a la formación de capital ficticio» (C.III. xxix:469)). Pese a lo que se suele decir, no es Marx el único economista clásico que utiliza este concepto (véase Perelman (1987)), si bien es quien le da una conceptualización más precisa. El adjetivar como «ficticio» al «capital» que para sus propietarios está colocado en esos títulos se debe a que, como sucede en el caso de la deuda pública, «no sólo porque la suma prestada al Estado ya no existe, sino además porque nunca tuvo como destino el de ser gastada como capital, el de invertirse, y sólo su inversión como capital habría podido hacer de ella un valor susceptible de conservarse a sí mismo» (C.III.xxix: 468), cosa que no sucede para los títulos cuyo carácter ficticio se manifestará «a partir del momento en que los títulos de la deuda se vuelven invendibles, la ficción se disipará» ${ }^{15}$. En cuanto a las acciones de empresas de la economía «real»y que por lo tanto «representan» un capital real, tienen también sin embargo para Marx un carácter ficticio o ilusorio pues «dicho capital no existe dos veces, una como valorcapital de los títulos de propiedad, de las acciones, y la segunda como capital invertido en realidad, o que se invertirá en las empresas. Sólo existe en esta última forma, y la

13 «No menos evidente resulta el hecho de que la ganancia de los banqueros es una deducción hecha sobre la plusvalía, pues sólo trabajan con valores ya realizados» (C.III.xix:334)

14 Hilferding, que fue el primer economista marxista que analizó en profundidad a estos intermediarios financieros, consideraba sus ingresos, a los que llamaba «ganancias del fundador» o del promotor, «una fuente de ganancias que nace únicamente de la transformación del capital productor de beneficios en la forma de capital productor de intereses», que no es «ni una estafa ni una indemnización o sueldo sino una categoría económica sui generis» (Hilferding,1963:114), una cualificación correcta en opinión de Sweezy (1972:285).

15 Resulta obvio que esa sería la razón que llevaría también a calificar como ficticio el capital colocado en todos los títulos respaldados por hipotecas, pues las viviendas no son capital productivo. Y, como dice Marx, esa ficción se ha disipado en la crisis de las hipotecas subprime. 
acción es un título de propiedad que da derecho a una porción correspondiente de la plusvalía que ese capital permitirá realizar» (C.III.xxix:470).

El proceso de valoración del capital-dinero invertido en la compraventa de este capital ficticio, a una tasa equiparable a la tasa de ganancia que obtienen los capitalistas dedicados a otras actividades industriales y comerciales, es decir, el que los inversores en los mercados secundarios de activos obtengan un rendimiento general o medio similar al de la tasa media de ganancia depende obviamente de que el valor de mercado, el precio o la cotización de los títulos que componen el capital ficticio crezca en la medida adecuada, de modo que se estime que podrían participar en la proporción requerida en la plusvalía (o, en general, el valor) que se genera en el proceso de reproducción social ${ }^{16}$. En el caso de la deuda pública es la capacidad impositiva del Estado la que posibilita esa participación en el valor social, en el caso de las acciones son los dividendos futuros de las empresas, en el caso de las obligaciones son los ingresos futuros de las mismas, en el caso de los títulos respaldados por hipotecas son los ingresos futuros de quienes solicitan los préstamos hipotecarios ${ }^{17}$.

Pero si ningún proceso de valoración del capital está enteramente garantizado para ningún capitalista individual, menos lo está para este tipo de capitalistas que invierten en capital ficticio, pues el precio, valor o cotización de estos títulos que componen el capital ficticio varía de forma independiente al valor de los activos reales subyacentes,

16 La razón es la misma que lleva a Marx a concluir que el precio de un recurso natural, una cascada que sirve como fuerza motriz, proviene de la plusvalía: «El salto de agua, lo mismo que la tierra y que cualquier otra fuerza de la naturaleza, no tiene valor en sí mismo, puesto que en él no se materializa trabajo alguno. Por lo tanto, tampoco tiene precio, que normaliter [normalmente] no es otra cosa que la expresión monetaria del valor. Cuando no hay valor, no puede, eo ipso [por lo mismo], haber expresión monetaria. Ese precio es la renta capitalizada» (C.III.xxxviii:643). Shaikh ha mostrado que «la tasa de retorno del mercado bursátil, que es una tasa intrínsecamente contingente o de corto plazo, está ligada a la tasa de rendimiento sobre la nueva inversión en el sector corporativo debido a los movimientos intersectoriales de capital entre los dos sectores. Las dos tasas se siguen la una a la otra de modo muy cercano, nunca igualándose pero siempre fluctuando la una en torno a la otra, exhibiendo medias y desviaciones standard muy similares» (Shaikh, 1997:399). Este enfoque, además, resulta mucho más explicativo estadísticamente que el convencional para dar cuenta de la alta volatilidad de las cotizaciones en la medida que, dada la observada estabilidad de los dividendos por acción, es la variabilidad de los precios de los títulos sobre quien recae fundamentalmente la tarea de mantener la tasa de retorno en el mercado bursátil en línea con la del sector corporativo.

17 Correspondientemente, los capitalistas que invierten en títulos hipotecarios obtendrían en parte sus beneficios de la plusvalía que incorporasen los salarios en la medida que estos fuesen superiores al valor de la fuerza de trabajo. 
caso de que los haya. Así, dice Marx: «En la medida en que la acumulación de estos títulos traduce la de ferrocarriles, minas, barcos de vapor, etc., expresa la expansión del proceso de reproducción real. Pero como duplicados, negociables a su vez como mercancías y que por lo tanto circulan como valores-capital, su valor es ficticio: puede aumentar o disminuir con absoluta independencia del movimiento de valor del capital real sobre el cual sus poseedores tienen un derecho» (C.III.xxx:480). «En rigor, todos estos efectos no son otra cosa que la acumulación de derechos, de títulos jurídicos sobre una producción futura, cuyo valor-dinero o valor-capital no representa capital alguno» (C.III.xxx:471). Ese valor-dinero del capital ficticio depende por un lado, del tipo de interés en la medida que es resultado de un proceso de capitalización, pero también de los beneficios esperados de las empresas (caso de las acciones), de las condiciones de demanda y oferta en los mercados secundarios, de la especulación, del fraude y la manipulación, etc. Concretamente, Marx señala que «el valor de mercado de los títulos es un valor especulativo, pues no lo determina la renta real de la empresa, sino la que se espera, calculada por anticipado» (C.III.xxviii:470) ${ }^{18}$

c) los capitalistas industriales, los encargados de la gerencia y la organización de la producción. Parte de sus tareas son productivas (Marx los llama frecuentemente capitalistas productivos) y generan como tales valor, pues son trabajo socialmente productivo, al igual que el trabajo del resto de los trabajadores. Así, Marx dice: «Si el trabajo del capitalista no deriva de la naturaleza exclusivamente capitalista del proceso de producción, es decir, si no termina con el capital mismo; si no se limita a la función de explotar el trabajo ajeno; si por el contrario, resulta de la forma social del trabajo, de la combinación y la cooperación de muchos individuos con vistas a un resultado común, es tan independiente del capital como esa forma misma» (C.III.xxiii:394). La remuneración por ese trabajo productivo que realizan los capitalistas es un salario exactamente igual que el que perciben los demás trabajadores, y así lo dice explícitamente Marx cuando considera el caso de la ganancia de una empresa cooperativa: su «ganancia,

18 Y señala además las condiciones en las que el capital ficticio sólo dependerá del tipo de interés: «Pero si se supone constante la tasa de valorización del capital real, o bien si no existe capital alguno, como en el caso de la deuda pública; si se admite que el rendimiento anual del título lo fija la ley y que por lo demás es lo bastante seguro, su precio sufrirá un alza o una baja en razón inversa a la tasa del interés» (Ibidem.) 
deducción hecha del salario del director que es, lo mismo que el salario de los otros obreros, una parte de las inversiones en capital variable» (CIII.xxxiii:395) ${ }^{19}$.

Pero, obviamente, los capitalistas industriales o productivos realizan también otro tipo de «trabajo», otro tipo de actividades, las típicas de los empresarios capitalistas: «La explotación del trabajo productivo cuesta esfuerzos, ya sea que los realice el propio capitalista, o que los hagan otros en su nombre» (C.III.xxiii:388), la remuneración que percibe el capitalista productivo por esa parte de sus tareas proviene de la plusvalía una vez que de esta ha salido el pago de los intereses y dividendos,remuneración de la financiación externa de la actividad productiva, y Marx la denomina ganancia o beneficio empresarial ${ }^{20}$.

Donde con claridad meridiana se observa a este tipo de capitalistas es en las sociedades por acciones. Una de las consecuencias de las sociedades anónimas es para Marx la separación entre la propiedad y el control ${ }^{21}$ («en las sociedades por acciones, la función se encuentra separada de la propiedad del capital»). En ellas se produce la

... transformación del capitalista realmente activo en un simple director y administrador de capital ajeno y de los propietarios de capital en simples propietarios, en simples capitalistas financieros. Aunque los dividendos que reciben incluyan el interés y la ganancia empresarial, es decir, la ganancia total (pues los emolumentos del dirigente son

19 Para recalcar que parte de las tareas de los capitalistas son trabajo productivo, Engels aquí, en una nota a pie de página, apunta lo siguiente: «en un caso que conozco, un fabricante, en quiebra después de la crisis de 1886, se había convertido en un asalariado, pagado por sus propios obreros. Después de la quiebra, la fábrica siguió siendo explotada por una asociación obrera, y el antiguo propietario fue tomado como director» (C.III. xxiii:394)

20 Marx continua señalando que «a diferencia del interés, su ganancia empresarial se le presenta como independiente de la posesión de capital, más bien como la culminación de sus funciones de no poseedor, de trabajador. Es inevitable que en su cabeza se forme la idea de que su ganancia empresarial — lejos de oponerse de una manera cualquiera al trabajo asalariado y de ser sólo trabajo ajeno no pagado— - se identifica más bien con una remuneración de trabajo o de vigilancia, wages of superintendence of labour El hecho de que el interés refluya al propio capitalista cuando no ejerce ninguna función y se conforma con poseer el capital le hace olvidar por completo, en contraste con su propio caso, que su función como capitalista consiste precisamente en producir plusvalía, es decir, trabajo no pagado, y ello en las condiciones más económicas. Olvida, además, que la ganancia empresarial afluye en cambio, al capitalista activo, aunque no sea el propietario del capital que hace fructificar» (C.III.xxiii:388)

21 Que Marx identifica cuarenta años antes que Veblen (The Theory of Business Enterprise, 1904) y setenta años antes que Berle y Means (The Modern Corporation and Private Property, 1932) 
o deberían ser un simple salario por un tipo particular de trabajo especializado, cuyo precio se regula en el mercado de trabajo, como cualquier otro), esa ganancia total sólo se percibirá en forma de interés, es decir, como simple remuneración por la propiedad del capital, que de tal manera queda separado por completo de su función en el proceso real de reproducción, tal como esta función, en la persona del director, queda separada de la propiedad del capital (C.III.xxvii:445).

Dicho de otra manera, en las sociedades por acciones y en general cuando hay una separación entre propiedad y control, aparece un nuevo tipo de «capitalistas» que no son propietarios del capital, que parte de su remuneración entra con pleno derecho en la categoría de salarios, y cuyas relaciones con los capitalistas-propietarios son, en cierto sentido, también antagónicas. Las relaciones sociales de producción pasan entonces de ser conflictivas con una base diádica (capitalistas/trabajadores) a tener una base triádica (capitalistas-propietarios/capitalistas-no-propietarios/trabajadores). Pero Marx da un paso más allá y distingue dentro del grupo de los capitalistas-no propietarios entre dos grupos, por un lado, el de los capitalistas-productivos en sentido estricto, aquellos dedicados a las tareas de gestión de la producción; y por otro, una suerte de «aristocracia» dentro de esos capitalistas-activos, de la que Marx habla en unos términos que suenan en estos tiempos, tras casi 150 años, muy actuales:

En las empresas por acciones, sobre la base de la producción capitalista, se desarrolla un nuevo fraude en relación con el salario del administrador. Al lado y por encima de los verdaderos administradores surge una gran cantidad de miembros de consejo de administración y de gerencia, para quienes la administración y la gerencia se convierten en realidad en simples pretextos para expoliar a los accionistas y para enriquecerse ellos mismos (C.III.xxiii:396) 22 .

Esa «aristocracia» estaría formada por aquellos managers o directivos de alto nivel de las grandes sociedades anónimas, cuya tarea, más que dirigirse a lograr que el proceso de valorización del capital en sus empresas fuese más eficiente por vía interna, es decir, por la mejora de gestión de la actividad productiva (y la extracción consiguiente de plusvalía), se dirige más bien a conseguirlo por una vía a la que se podría llamar

\footnotetext{
22 Marx añade que «La remuneración de los directores de estas sociedades, por cada sesión semanal, es por lo menos una guinea (21 marcos)», ¿qué hubiera pensado de conocer las fabulosas compensaciones de los miembros de los CEO de las grandes sociedades anónimas de hoy en día?
} 
externa, es decir, buscando que los mercados bursátiles asignen una cotización elevada al valor bursátil de las mismas, es decir, buscando valorizar el capital ficticio de las empresas. Esas actividades sitúan a este tipo de capitalistas gestores de las empresas más bien dentro del grupo de los capitalistas comerciales intermediarios en los mercados bursátiles. Se trata de «una nueva aristocracia financiera, una nueva especie de parásitos, en forma de promotores, especuladores y directores simplemente nominales. Todo un sistema de fraudes y estafas por medio de la promoción de las corporaciones, de la emisión y tráfico de acciones» (C.III.xxiii:447)

Ahora bien, las relaciones entre estos cuatro grupos (incluyendo a los terratenientes y otros propietarios de recursos naturales) que pugnan por repartirse la plusvalía generada por los trabajadores productivos de una economía son necesariamente conflictivas pues todos compiten en cada momento entre sí por repartirse una determinada cantidad de plusvalía y en establecer las condiciones para quedarse con una mayor parte de la plusvalía que se genere en el futuro. Ya Ricardo había señalado la contraposición de intereses entre terratenientes inactivos y las clases productivas formadas por capitalistas y trabajadores. Y lo que hace Marx es ampliar ese juego de rivalidades y antagonismos al resto de los grupos señalados.

Dejando fuera la oposición entre terratenientes y capitalistas, ya considerada por Ricardo, nos centraremos aquí en las oposiciones entre los grupos de capitalistas a tenor de la importancia que estas rivalidades puedan tener en el desencadenamiento de una crisis financiera. Una primera oposición, de carácter puede decirse que débil, es aquella que enfrenta a los capitalistas comerciales dedicados al tráfico de mercancías y de dinero con los industriales o productivos. Se trata de una relación donde los elementos de cooperación tienden a superar a los de rivalidad pues los capitalistas industriales consideran un gasto necesario los gastos de comercialización y es para ellos una opción menos costosa «externalizar» esas actividades que hacerlas dentro de las empresas industriales.

Marx, por ello, se centra en la relación que enfrenta a los otros grupos de capitalistas. Las relaciones entre los capitalistas financieros y los productivos en estricto sentido, no sólo no son armoniosas por ser sus remuneraciones respectivas, intereses y ganancias empresariales, «dos categorías distintas de ganancia que tienen relaciones diferentes con el capital» (C.III.xxiii:384), sino que entre ellos, hay «algo» más ya que, «para el capitalista productivo que trabaja con capital prestado, la ganancia bruta se divide en dos partes: el interés que debe pagar al prestamista y un excedente que es su propia parte de la ganancia» (C.III.xxiii:381). Para el capitalista activo por lo tanto, 
... quien representa la propiedad capitalista es el capitalista financiero y prestamista. El interés que debe pagar representa, entonces, la parte de la ganancia bruta que corresponde a la posesión del capital como tal. Por el contrario, la porción de la ganancia correspondiente al capitalista activo aparece ahora como ganancia empresarial, surgida con exclusividad de las operaciones y funciones que el capital cumple en el proceso de reproducción, y por lo tanto, nacida, en especial, de las funciones que el capitalista activo desarrolla como empresario en la industria o el comercio. Para él, el interés es el simple fruto de la propiedad del capital, el fruto del capital en sí, fuera de su proceso de reproducción, en la medida que en que no «trabaja», en que no se encuentra en funciones, en tanto que la ganancia empresarial se le aparece como el resultado exclusivo de las funciones que lleva a cabo con el capital, como fruto del movimiento y del proceso de trabajo. Ve este proceso como resultado de su propia actividad, por oposición a la inactividad, a la no participación del capitalista financiero en el proceso de producción. Esa distribución cualitativa entre las dos partes de la ganancia bruta (en el sentido de que el interés es el fruto del capital en sí, de la propiedad capitalista , con abstracción del proceso de producción, y que la ganancia empresarial es el fruto del capital en movimiento, que actúa en el proceso de producción y que por lo tanto cumple con el papel activo que su empleador le hace representar en el proceso de producción); esa distribución cualitativa, decimos, no es en modo alguno una concepción puramente subjetiva del capitalista financiero por una parte , y por la otra del industrial. Se basa en un hecho objetivo, pues el interés refluye hacia el capitalista financiero, el prestamista, quien es apenas el propietario del capital y representa, entonces, la propiedad capitalista antes del proceso de producción y fuera de él. La ganancia empresarial afluye al capitalista simplemente activo, que no es el propietario del capital (C.III.xxiii:382-3).

Pero la oposición entre capitalistas financieros y capitalistas productivos no se reduce al conflicto distributivo en torno al reparto de la plusvalía generada en el proceso de producción, sino que, en los casos en que el capitalista activo no es propietario del capital, es decir, en los casos en que la propiedad legal de las empresas es de los capitalistas financieros (como sucede en las sociedades anónimas), existe como se ha señalado una clara separación entre propiedad y control a la que Marx da el rango de antagonismo cualitativo ( «La división cuantitativa de la ganancia bruta se convierte aquí en cualitativa» dice Marx). Estos dos tipos de capitalistas, «el capitalista financiero y el productivo, se enfrentan en la realidad no sólo como personas jurídicamente distintas, sino también como individuos que representan en el proceso de producción papeles muy distintos» (C.III.xxiii:381), como se refleja en su posición relativa respecto a los trabajadores pues sucede que la oposición entre el capital y el trabajo asalariado 
... queda esfumada en la forma del interés pues el capital que rinde intereses no se opone, como tal, al trabajo asalariado sino al capital en funcionamiento. El capitalista prestamista se relaciona de manera directa con el realmente activo en el proceso de reproducción, y en modo alguno con el asalariado, que se encuentra desposeído de los medios de producción bajo la producción capitalista. El capital que produce intereses es el capital-propiedad frente al capital-función. Pero mientras el capital no se emplea de manera activa, no explota a los obreros y no se encuentra en oposición al trabajo (C.III.xxiii:387).

Las relaciones entre los capitalistas financieros y los capitalistas comerciales dedicados a la intermediación en los mercados financieros tampoco son siempre armoniosas. En varios lugares, Marx atiende al hecho de que una subida de los tipos de interés, que favorece a los prestamistas, devalúa el valor capitalizado de los títulos que componen el capital ficticio, y por ende, desvaloriza el capital de los intermediarios que los habían comprado 23 .

Finalmente, la relación entre capitalistas productivos y capitalistas financieros e intermediarios financieros vía el sistema financiero puede ser tan conflictiva como para abocar en una crisis económica:

El sistema de crédito, cuyo centro son los bancos llamados nacionales, y los prestamistas y usureros que gravitan en torno a ellos, representa una enorme centralización, y otorga a esta clase de parásitos un poder fabuloso; no sólo el de diezmar periódicamente a los capitalistas industriales, sino además el de intervenir en la forma más peligrosa en la producción real. Y esta banda nada sabe acerca de la producción y nada tiene que ver con ella. Las leyes de 1844 y 1845 son pruebas del creciente poder de estos bandidos, a quienes se unen los financieros y stock-jobbers [especuladores de la Bolsa] (C.III.xxxiii:545).

23 «durante las fases desfavorables del ciclo industrial, la tasa del interés puede elevarse a un nivel tal que absorba por el momento toda la ganancia de algunas ramas aisladas que actúan en condiciones especialmente desfavorables. Al mismo tiempo se derrumban los precios de los fondos del Estado y de otros valores. En esas ocasiones los capitalistas financieros llevan a cabo compras en masa de esos títulos devaluados, que en las fases posteriores no tardarán en recuperar y superar su nivel normal. Después se los lanza al mercado, y esa es la manera en que dichos capitalistas se apropian de una parte del capital-dinero del público. La porción que no se vende rinde intereses más elevados, pues se ha comprado por debajo de su precio» (C.III.xxx1:504) 
Y de lo que se trata ahora es de ver cómo estos «bandidos», en opinión de Marx, ejercen ése su «fabuloso poder» para poner en riesgo el desenvolvimiento de las economías reales.

\section{LAS CRISIS FINANCIERAS}

En multitud de lugares en El Capital describe Marx el proceso por el que una crisis en el sistema financiero se convierte en una crisis económica, es decir, cómo se produce el parón de un período de expansión económica generado gracias a la expansión financiera cuando se produce un colapso en el sistema financiero, cómo desde allí se propaga al resto de los sectores productivos. Sirva como ejemplo el siguiente:

El crédito hace que el reflujo en forma de dinero sea independiente del momento del reflujo real, se trate del capitalista industrial o del comerciante. Cada uno de ellos vende a crédito, por consiguiente enajena su mercancía antes de que se reconvierta para él en dinero, es decir, antes de que refluya a él en esa forma. Por lo demás, compra a crédito, y entonces el valor de su mercancía s reconvierte para él, ya sea en capital productivo o en capital-mercancía, mucho antes que dicho valor se haya convertido en realidad en dinero, antes inclusive de que los precios de las mercancías hayan vencido y se paguen. En los períodos de prosperidad, el reflujo se desarrolla con facilidad y sin complicaciones. El minorista paga sin vacilaciones al mayorista, éste al fabricante, éste al importador de materias primas, etc. La apariencia de reflujos rápidos y seguros se mantiene siempre, durante cierto tiempo, después que dejaron de serlo en realidad, gracias al crédito puesto en marcha, ya que los reflujos de crédito remplazan a los verdaderos. Los bancos empiezan a presentir el peligro en cuanto sus clientes depositan más letras que dinero (C.III.xxviii:455).

Pero, ¿por qué se produce la crisis en el sector financiero? ¿por qué el proceso de expansión productiva facilitado o generado por el crédito llega a su fin? Está claro que «en algún lugar misterioso — dice Marx - la mercancía queda invendida, o bien los acopios de todos los productores e intermediarios llegan poco a poco a la saturación». Cierto, eso es una crisis, que «estalla cuando los reingresos de los comerciantes que venden en los mercados lejanos (o cuyos acopios se han acumulado en el interior del país) se vuelven tan lentos y parsimoniosos, que los bancos reclaman sus deudas, o los pagarés recibidos por las mercancías compradas vencen antes que se haya producido la reventa. Entonces comienzan las ventas forzadas, las ventas con fines de pago; y en ese 
momento el krach pone brusco fin a la prosperidad aparente» (C.III.xviii:319). La crisis, el crac, hay que recalcarlo, se produce no porque se desplomen las ventas inicialmente ${ }^{24}$ sino porque el sistema de crédito se desploma: «las crisis no estallan primero en el comercio minorista que tiene relación directa con los consumidores, sino en las esferas del comercio mayorista y en los bancos, puesto que éstos ponen a disposición de aquél el capital-dinero social».

Puestos a buscar una posible explicación de ese desplome del mercado crediticio, un evidente primer culpable sería un ascenso en el tipo de interés causado por cualesquiera razón. Un ascenso en el tipo de interés ${ }^{25}$ llevaría a una contracción de la demanda de créditos así como a una mayor dificultad para pagarlos por parte de los capitalistas industriales o comerciales dados sus beneficios, dificultades para responder a los préstamos que a su vez llevarían a subidas ulteriores de los tipos. Las crisis se explicarían consecuentemente por un ascenso progresivo en la tasa de interés que podría desencadenar un proceso acumulativo de contracción general del crédito y tras él, vendría una insuficiencia de demanda efectiva que interrumpiría los procesos de valoración del capital industrial, con los negativos efectos sobre los niveles inversión, producción y empleo. Pero, para Marx, no parece que se pueda achacar directamente a las subidas del tipo de interés el desencadenamiento de una crisis puesto que si bien hay correspondencia entre subidas de tipos y expansión, la crisis acontece antes de que los tipos alcancen su valor máximo:

Cuando se consideran los ciclos económicos en los cuales se mueve la industria moderna: estado de reposo, creciente animación, prosperidad, superproducción, crisis, estancamiento, estado de reposo, etc (un análisis más profundo de estos ciclos se encuentra fuera de nuestro tema) se advierte que un nivel poco elevado del interés corresponde a los períodos de prosperidad y de ganancia extraordinaria; que la elevación del interés corresponde a la transición entre la prosperidad y su contrario, y que, por último, el máximo de interés, hasta el extremo límite de la usura, corresponde al perío-

\footnotetext{
24 Es decir, que el origen de una crisis financiera no hay que buscarlo en una caída en la demanda efectiva

25 Otro ejemplo causado por un aumento de la preferencia por la liquidez: «Su valor [el de los títulos] es siempre el de su renta capitalizada, es decir, su interés vinculado con un capital ilusorio, sobre la base de la tasa de interés existente. En las épocas de mercado de dinero duro, los precios de esos títulos, entonces, se derrumbarán por dos razones; primero, porque la tasa de interés asciende, y luego porque se los lanza al mercado en grandes cantidades, por parte de quienes desean realizarlos en dinero» (C.III.xxix:471).
} final. 
do de crisis La tasa de interés llega a su punto más elevado durante las crisis, cuando es preciso tomar prestado a cualquier precio para poder $\operatorname{pagar}^{26}$. (C.III.xxii:370).

Es decir, que es la contracción del crédito lo que fuerza la subida final de de los tipos que acelera la gravedad de la crisis y ayuda a difundirla por la economía real por sus efectos contractivos sobre la demanda efectiva. Pero, si la subida de tipos es consecuencia y no causa de la crisis financiera, la cuestión vuelve a ser la original: ¿por qué se produce el desplome del crédito? Ciertamente, ese desplome puede situarse en una caída en la demanda crediticia asociada a dificultades en los procesos de valoración del capital en la esfera de la producción que lleven a los capitalistas a disminuir sus demandas de créditos. Con esto se volvería a las crisis «tradicionales», a aquellas que tienen su origen en la esfera productiva y se manifiestan en la esfera de la financiación.

Pero aquí, en el Libro III de El Capital, Marx señala la posibilidad de que la caída en los créditos no se origine en la esfera de la producción sino en la de la circulación, en el propio sistema de crédito; si el crédito se desploma no es por tanto por una caída en la demanda de créditos, sino en su oferta:

No es en modo alguno la fuerte demanda de préstamos la que distingue el período de depresión del de prosperidad, sino, más bien, la facilidad con la que se satisface dicha demanda en tiempos de prosperidad y la dificultad que encuentra en períodos de depresión.

\section{Y Marx agrega:}

Precisamente el inmenso desarrollo del sistema de crédito durante el período de prosperidad, y por consiguiente, también el enorme aumento de la demanda de capital de préstamo y la buena voluntad con la cual la satisface la oferta correspondiente en dichos períodos, son los que provocan una escasez del crédito durante un lapso de depresión. Lo que diferencia a ambos períodos no se encuentra, por lo tanto, en la diferencia de volumen de la demanda de préstamos (C.III.xxviii:457).

\footnotetext{
26 Que para Marx no hay una conexión obligada entre movimientos en los tipos y el «estado de los negocios» resulta claro tras el comentario que Marx hace a continuación de la cita anterior: «Pero puede ocurrir que un interés poco elevado coincida con un estancamiento de los negocios, en tanto que el reavivamiento de éstos vaya acompañado por un interés en ligero ascenso».
} 
La oferta de créditos la realiza el sistema bancario, y es a él al que es necesario dirigirse para indagar por las causas en las restricciones para la financiación crediticia. Marx define el capital de los bancos como compuesto de dinero en especie, oro y billetes y títulos, a su vez, conformados por papeles comerciales o letras y «valores públicos: bonos del Estado, títulos del Tesoro, acciones de todo tipo. En una palabra, valores que rinden un interés» (C.III.xxix:467), es decir, capital ficticio:

Por consiguiente, la mayor parte del capital del banquero es puramente ficticia y consiste en títulos de deuda (letras de cambio), bonos del estado (que representan el capital invertido) y acciones (giros sobre futuras rentas). En este sentido, es preciso no olvidar que el valor-dinero del capital que representan esos títulos encerrados en las cajas fuertes del banquero es desde todo punto de vista ficticio, aunque sean giros sobre rentas garantizadas (como ocurre con los bonos del Estado) o títulos de propiedad de un capital real (como por ejemplo las acciones), y que dicho valor se rige por leyes que difieren de las que determinan el del capital real, que por lo menos una parte de ellas representan (C.III.xxix:472).

En consecuencia, la capacidad de otorgar financiación de los bancos depende del valor de este capital ficticio, valor que, en el caso de las cotizaciones de las acciones, «puede aumentar o disminuir con absoluta independencia del movimiento de valor del capital real sobre el cual sus poseedores tienen un derecho» (C.III.xxx:480).

Y Marx apunta que alguno de estos títulos que componen el capital ficticio no representen nada: «Señalemos, de paso, que en modo alguno está excluido que representen un simple fraude» (C.III.xxix:470).

Dicho de otra manera, el sistema de crédito depende directamente del valor del capital ficticio, de modo que los aumentos de su valor, permiten expandir la oferta de créditos y con ello se posibilita la expansión económica. Por el contrario, una caída en el valor del capital ficticio, al restringir la oferta de créditos genera un proceso contractivo, que adicionalmente afecta también a la demanda de créditos en la medida que esos títulos son usados por los demandantes de crédito como garantía. El precio de los títulos que componen el capital ficticio

... baja con el alza del interés. Desciende además, a causa de la escasez general del crédito, que obliga a sus poseedores a lanzarlos en masa al mercado para obtener dinero. Y desciende, por último en el caso de las acciones, ya sea a consecuencia de la reducción de las rentas a que dan derecho, o bien debido al carácter especulativo de las empresas a las que con suma frecuencia representan. Las crisis reducen enormemente 
ese capital-dinero ficticio, y por lo tanto, el poder de quienes lo poseen, de tomar dinero en el mercado, sobre la base de ese capital. La reducción que sufren los cursos de esos valores en los boletines de cotización no tiene, sin embargo, relación con el capital real que representan ${ }^{27}$, sino que, en cambio, ejerce una considerable influencia sobre la capacidad de pago de los poseedores de ese capital (C.III.xxx:495).

En suma, son las crisis bursátiles las que desencadenan las crisis financieras. Pero para que éstas sean autónomas y no mero reflejo en el sector financiero de las crisis en la esfera de la producción (asociadas por tanto a una disminución de la tasa de explotación y/o de la tasa de ganancia), es necesario que su desencadenante sea propio o «interno», y aquí el estallido de una burbuja especulativa aparece como la causa más probable de la desvalorización del capital ficticio en manos de los bancos y otros intermediarios financieros y de los particulares. Marx así lo afirma explícitamente:

En un sistema de producción en el cual todo el complejo edificio del proceso de reproducción se basa en el crédito, si éste se interrumpe en forma repentina y sólo tienen curso los pagos en efectivo, es evidente que debe producirse una crisis, una carrera en procura de medios de pago. En consecuencia, a primera vista, toda la crisis se presenta como una simple crisis de crédito y de dinero $\mathrm{Y}$ en rigor sólo se trata de la convertibilidad de las letras de cambio comerciales en dinero. Pero en su mayoría, esas letras representan compras y ventas reales, cuyo volumen supera con mucho las necesidades de la sociedad, lo cual en definitiva, constituye la base de toda la crisis. Pero al mismo tiempo, una enorme cantidad de ellas representa sólo negocios especulativos, que al surgir a la luz del día estallan como pompas de jabón. O bien se trata de especulaciones realizadas con capital ajeno, pero que no tuvieron éxito; por último, son capitales-mercancía que se han depreciado o que inclusive son invendibles, o reingresos de dinero que ya no podrán realizarse (C.III.xxx:491-2).

En consecuencia, para Marx, la secuencia de una crisis financiera de carácter autónomo comienza por la financiación especulativa por parte del sistema de crédito de

27 En otro pasaje, Marx afirma que «si la depreciación o el aumento de valor de estos títulos no tiene relación con el movimiento del valor del capital real que representan, la riqueza de una nación es tan grande antes de su depreciación o alza como después». Pero esos sólo puede pasar «si esa depreciación no traduce una detención real de la producción y del tránsito por los canales y ferrocarriles, o el abandono de construcciones ya iniciadas, o la dilapidación de capital en negocios carentes de valor alguno, el estallido de estas pompas de jabón de capital-dinero nominal no empobrecería a la nación ni en un centavo» (C.III.xxix:471) 
procesos de acumulación en sectores «equivocados» o en un volumen desproporcionado en el curso de la fase expansiva del ciclo económico. En la medida que el sector o sectores económicos implicados por esta expansión desordenada sean lo suficientemente importantes o las interrelaciones entre los agentes del sistema de crédito lo suficientemente estrechas y generales, el estallido de la burbuja que acontece cuando esas inversiones reales no rinden la tasa de ganancia esperada (o la media de la economía) se manifiesta en el sector financiero en el desmoronamiento de la cotización de los títulos emitidos para financiarlas lo que afecta negativamente a la capitalización del sistema bancario y en general de todo el sistema financiero ${ }^{28}$ generando una contracción crediticia que lleva la crisis al resto de los sectores. Las crisis financieras arrancan, por tanto, en una crisis de desproporcionalidad en la acumulación de capital en el sector real de la economía, desproporcionalidad generada sin embargo en las posibilidades que ofrece el sistema de crédito para usar una fuente de valoración del capital a corto plazo en los procesos de circulación del capital ficticio en los mercados bursátiles «independiente» de la valoración del capital en los procesos de producción mediante la extracción de plusvalía. Es condición imprescindible para que se de esa acumulación «equivocada» o «excesiva» que los procesos de inversión tanto financiera como real estén dirigidos por el subgrupo de capitalistas activos que controlan las empresas sin ser sus propietarios reales:

Si el sistema de crédito aparece como la palanca principal de la superproducción y de la superespeculación comercial, ello sólo se debe a que el proceso de reproducción, elástico por naturaleza, se encuentra forzado aquí hasta sus límites extremos , dado que una gran parte del capital social la utiliza quienes no lo poseen y que, por consiguiente, encaran las cosas de manera muy distinta a como lo hace el propietario, que, si es activo él mismo, sopesa con ansiedad los límites de su capital privado (C.III.xxvii:449).

En opinión de Marx, por consiguiente, el subgrupo de los capitalistas activos que operan en los mercados bursátiles, «encara» su actividad para conseguir beneficios de

\footnotetext{
${ }^{28}$ Pues hay que tener en cuenta que los distintos agentes del sistema de crédito están ligados entre sí, como lo están los bancos a resultas del proceso de creación de dinero bancario. Marx expresa esta interacción del modo siguiente: «A medida que se desarrolla el capital productor de interés y el sistema de crédito, todos los capitales parecen desdoblarse, y en algunos casos inclusive triplicarse, gracias a las distintas maneras en que un mismo capital, o inclusive el mismo crédito, aparece en distintas manos y en formas diferentes» (C.III. xxix:473).
} 
modo distinto a los otros: aquellos implicados en la gestión de los procesos de producción. En vez de buscar la valoración del capital dentro del proceso de producción mediante la transformación del capital-dinero de los capitalistas-propietarios en capital-productivo y la consiguiente extracción de plusvalía, su objetivo es la obtención de beneficios mediante la transformación de capital-dinero en títulos o capital ficticio y la especulación con él mismo como medio de apropiarse del valor o la plusvalía generada en otros sectores ${ }^{29}$ : «Las ganancias y pérdidas a consecuencia de las fluctuaciones de precio de estos títulos, así como su centralización en manos de los reyes de los ferrocarriles, etc., serán - así lo exige la naturaleza de las cosas- cada vez más el resultado de la especulación, que aparece en lugar del trabajo como el modo original de adquirir el capital, y que también reemplaza a la violencia directa» (C.III.xxx:481).

Dada la época en que escribe Marx sólo tiene ante sí algunos ejemplos concretos de esos manejos especulativos, y de ahí la falta de un modelo detallado del comportamiento de estos capitalistas. Una generación más tarde, en 1904, Thorstein Veblen describía esos manejos de una forma que, seguramente, hubiera sido aceptada por Marx:

... los hombres que tienen el manejo de la empresa industrial, capitalizada y cotizable en el mercado, podrán provocar una diferencia entre la capacidad de ganancia putativa y la real por medio de expedientes bien conocidos y aprovechables para el caso. La información parcial, así como la información errónea, suministrada con sagacidad en alguna coyuntura crítica, resultará de gran importancia para producir una diferencia temporal a favor de este tipo, y permitir así a los directores comprar y vender las acciones de la firma con ventaja para sí mismos. Si son hombres sagaces, como en general suelen serlo, tendrán el propósito de manejar los asuntos de la empresa con miras a comprar y vender ventajosamente su capital más que con vistas a la prosperidad futura de la misma o a la venta lucrativa continuada de la producción de bienes o

29 «Lo que arriesga el comerciante mayorista que especula no es su propiedad privada sino la propiedad social. La frase hueca sobre el origen del capital en el ahorro es igualmente sórdida, puesto que exige que otros ahorren para él», y, más adelante, «el crédito da cada vez más, a esos pocos, el carácter de puros especuladores industriales. Como la propiedad existe entonces en forma de acciones, su movimiento y trasmisión se convierten en el simple resultado del juego de la Bolsa, donde los peces pequeños son devorados por los tiburones y los corderos por los lobos de la Bolsa He aquí los dos aspectos de la característica inmanente del sistema de crédito: por una parte, desarrollar el motor de la producción capitalista, es decir, el enriquecimiento por explotación del trabajo ajeno, para convertirlo en el sistema más puro y monstruosos de especulación y de juego, y para limitar cada vez más el pequeño número de quienes explotan las riquezas sociales» (C.III. xxvii:447,448,449) 
servicios, originada en el uso industrial de este capital. Los intereses de los directores de una sociedad anónima moderna no necesitan entonces coincidir con los intereses permanentes de dicha sociedad como empresa en marcha, ni tampoco con los intereses que la comunidad tiene en el eficiente manejo de la firma como empresa industrial (Veblen, 1965:132-3) $)^{30}$.

Y, finalmente, ¿qué puede provocar el estallido de la burbuja especulativa y desencadenar el proceso de desvalorización del capital financiero y la consiguiente crisis financiera y económica? Cabe una variedad de motivos. Puede ser el incumplimiento real de las expectativas que de la mano de la especulación con los títulos guiaron la acumulación de capital hacia un sector, pero puede ser también la subida en el tipo de interés, o, como Marx constata en la crisis inglesa de 1847 un incremento de los pagos por las importaciones de granos consecuencia de una mala cosecha, puede ser un avance técnico (el telégrafo) que permite que la información fluya más rápidamente con lo que desparece una de las fuentes de las ganancias especulativas. No importa la causa concreta, la razón es la misma, el capital-dinero allí invertido no alcanza la valoración esperada, no obtiene la plusvalía que le garantice una tasa de ganancia media, pierde valor y arrastra al sistema crediticio generando a partir de ahí una crisis de demanda efectiva.

Una vez desencadenada la crisis, comenzada ya la fase depresiva, de poco valen para Marx los remedios meramente monetarios que recapitalicen al sistema bancario:

Todo este sistema artificial de extensión forzada del proceso de reproducción no puede remediarse, por supuesto, haciendo que un banco, por ejemplo, el de Inglaterra, entregue entonces a todos los especuladores, en papel moneda emitido por él, el capital que les falta y compre por su antiguo valor nominal todas las mercancías depreciadas (C.III.xxx:492).

siendo la razón el que la crisis ha sido consecuencia de una acumulación desproporcionada en el sector real guiada por el movimiento especulativo del capital ficticio.

30 Marx habla, por ejemplo, de cómo el estallido de la burbuja de los ferrocarriles en 1847 afectó a los «fabricantes y los negociantes de Manchester que habían inmovilizado una parte de su capital empresarial normal en la compra de acciones ferroviarias y que dependían, para la marcha de sus negocios, de los préstamos de capital; su floating capital, en efecto, había quedado fijado y lo necesitaban para hacer frente a las consecuencias» (C.III.xxx:488) 
La salida de la recesión requiere pues de la restauración de las condiciones para una acumulación equilibrada.

\section{CONCLUSIONES}

Ha sido habitual dudar de la existencia de un tipo de crisis financieras de carácter «autónomo» en Marx en la medida que su análisis y metodología se centran en el estudio de las contradicciones en el funcionamiento de las economías capitalistas consecuencia de las relaciones antagónicas entre capitalistas y trabajadores cuyo lugar propio son las relaciones de producción. Y, ciertamente, las crisis financieras son fundamentalmente para Marx manifestación en la esfera de la circulación mercantil, del dinero y del crédito de esos conflictos subyacentes. Sin embargo, la lectura de los capítulos del Libro III de El Capital dedicados al análisis del sistema de crédito en una economía donde el peso e importancia económica de las sociedades anónimas es creciente revela que Marx era consciente de que la competencia entre distintos grupos de capitalistas (distintos por ser distintas sus «funciones» económicas) por repartirse la plusvalía generada en los procesos de producción generaba unos antagonismos que podían desembocar en crisis financieras «autónomas», es decir, independientes de la oposición fundamental entre capitalistas y trabajadores.

Concretamente, Marx acentuaba como el sistema de crédito se traducía en un crecimiento de lo que el llamaba capital ficticio, y hoy se llamaría titulización, cuya valoración en los mercados de valores abría un nuevo campo para la pugna por el reparto de la plusvalía entre los capitalistas en función de las posiciones que se adoptasen respecto a los movimientos de las cotizaciones de los títulos. Tal cosa, que podría tener sólo un efecto meramente redistributivo, se convertía en un factor de inestabilidad cuando esos movimientos de carácter especulativo se tradujesen en distorsiones de los procesos de acumulación que llevasen la inversión hacia sectores no adecuados. La pérdida de valor de esas inversiones que inevitablemente tendría lugar conforme no se cumpliesen las expectativas puestas en ellas, la desvalorización del capital ficticio se vería amplificada por el sistema de crédito en forma de crisis de financiera o de crédito que acabaría afectando al sector real de la economía.

Finalmente, no es necesario incidir en demasía en que la narración de esta visión marxista de las crisis financieras se adecua perfectamente a una crisis como la que se está padeciendo en la actualidad. La titulación de los créditos hipotecarios en EE.UU. que permitió la generación de una burbuja inmobiliaria que llevó a la concesión de hipotecas subprime parecen un ejemplo claro de cómo la valoración especulativa del 
capital ficticio conduce la acumulación de capital a lugares donde no debería haber ido. El estallido de la burbuja, la contracción del crédito consiguiente y la recesión económica no hubieran extrañado nada en absoluto a Marx.

\section{REFERENCIAS BIBLIOGRÁFICAS}

Hilferding, R., El capital Financiero, Madrid, Tecnos, 1963.

Perelman, M., Marx's Crises Theory. Scarcity, Labor, and Finance, Nueva York, Praeger, 1987.

Marx, K., El Capital. Crítica de la economía política, Libros I, II, III, Buenos Aires, Ed. Cartago, 1973.

ShaikH, A., «The Stock Market and The Corporate Sector. A profit-based approach», en $\mathrm{Ph}$. Arestis, G. Palma y M. Sawyer, Markets, Unemployment and Economic Policy. Essays in Honour of Geoff Harcourt, vol. 2, Londres, Routledge, 1997, págs. 389-404.

Sweezy, P. M., La Teoría del Desarrollo Capitalista, México, Fondo de Cultura Económica, 1972.

Veblen, Th., Teoría de la Empresa de Negocios, Buenos Aires, EUDEBA, 1965. 